\title{
Cost Management in Translation
}

\author{
Dr. Seyed Mohammad Hosseini-Maasoum
}

Department of Linguistics \& Foreign Languages, Payame Noor University, I.R. Iran

\section{Mostafa Ghazanfari}

Department of English, Quchan Branch, Islamic Azad University, Quchan, Iran

Doi:10.5901 / ajis/2013.v2n1p161

\section{Abstract}

Translation management is a modern approach toward translation industry in order to improve performance, quality and to reduce the use of resources such as human resources, cost and time. In this study, the main goal is to identify the standard cost management procedures and to apply cost management knowledge to translation studies. The study is based on Project Management Institute (PMI) standards which consist of 9 different management knowledge areas such as time, cost, procurement, quality, human resources, integration, communication, and risk management. The findings are expected to shed some light on cost management and its related issues in translation studies.

Key words: translation studies, translation management, cost management, PMI

\section{Introduction}

Translation project management is the solution to the new face of translation activities. People today can expect an organized set of works from translation agencies, which have an organizational structure based on modern project management. It is associated with planning, executing, controlling, and delivering a final translation to a client.

There are many reasons to justify the focus on project management; the primary one is the nature of translation that is normally carried out as a project (Dunne \& Dunne, 20II, p. 25). The Project Management Institute defines a standard framework for handling every project type. According to PMI (2008, p. 434), project is a sequence of unique, complex and connected activities having one goal to be completed by a specific date. Furthermore, PMI methodology consists of project management body of knowledge (PMBOK) that comes next in this thesis.

PMBOK is a comprehensive project management standard that provides a generic management framework that can be applied to any industry (Dunne \& Dunne, 201I, p. 92). Therefore, it can provide a theoretical model to apply project management elements to translation applied aids introduced earlier by Holmes (1972) and Pym (1998).

$\mathrm{PMBOK}$, in summary, includes management of cost, time, procurement, human resource, quality, risk, scope, and integration. Project Management Institute (PMI) offers PM frameworks that can be used in any industry like language industry. Project Management Body of Knowledge, PMBOK for short, was owned, prepared, and published by the PMI. This international and reliable guide offered five processes such as initiating, planning, executing, monitoring and controlling, and closing (PMI 2008). 
Cost management is the process of managing the costs involved in translation project. The central aim is to provide "the same value to customers at a lower cost or provision of a higher value at the same cost” (Dutta, 2005, p. 29). Cost is an important factor for a product to be successful; as the technology matures, the real competition is almost based on cost or price. Therefore, cost management is being increasingly implemented in various steps of project life-cycle to eliminate the redundant costs of the project in order to gain higher productivity and competitive price. Translation project like any project deals with challenge of cost management.

\section{Cost Management in Translation}

Mackay (2006, p. I0I) elaborated the most common payment terms for translators in the United States where freelance translators will be paid within 30 days of invoice date or so-called "Ne 30". Although these payment terms are far better than Net 60 or 90, as your cash flow is only a month behind your work flow; * it is still far from the online era.

Nowadays, with the improvement in computer industry, everything tends to go online in order to gain access to more resources (human or economic). Therefore, payments with (at least) 30 days delay would not work in modern translation management approaches. European clients still pay in terms of Net60 or longer and this shows their lack of trust in the system or putting less value for translation.

Anyhow, the best approach is to maximize translators' chances of getting paid on time on the basis of a well-organized invoicing system which is called "cost management tools". Cost management can print out invoices with pre-defined standards such as rate, word count, total amount and project description.

It must also be remembered that a translation company's rates will always be higher than those of a freelance translator, simply because the company has all kinds of additional costs (i.e. sales, accounting, IT maintenance etc.) and overheads that the freelancer does not have.

\section{Why Cost Management?}

Translation activity is a job of receiving and completing project offers. Some customers ask for the overall project cost at the beginning while others expect invoices at the end. Like SamuelssonBrown(2006, p. I2I) described, as price pressure reigns it is invariably the translator who offers the lowest price who will be offered the job. While there are good translators who will accept low prices, the risk is that customers will accept lower prices from less experienced translators. Cost management can serve as an important role in creating competitive translation rates in order to decrease the impact of "luxury translation" elements. The customer should understand the value of quality in translation and respect a reasonable higher translation price offered from translators with more experience.

Moreover, in the current competitive market where the range of translators is from freelancers to employees of translation agencies, cost management can help beginners to survive. Also, many translation projects happen to experience "possible overruns in the event that one or more tasks cost more than expected” (Dunne \& Dunne, 20II, p. 8I). Therefore, cost management is a proper way to keep things under control while translating different projects.

\section{Cost Management Processes}

Cost management in translation as the name implies deals with the costs and budgets of a translation project. According to Kim Heldman (201I, p.47) this knowledge area consists of three processes as follow: 
Table I. Project cost management processes

\begin{tabular}{ll}
\hline Process Name & Project Management Process Group \\
\hline Estimate Costs & Planning \\
Determine Budget & Planning \\
Control Costs & Monitoring and Controlling \\
\hline
\end{tabular}

Many project managers paid costs when creating their budget to cushion against possible overruns in the event that some of the tasks cost more than expected (K.J \& S.E. Dunne, 20II, p.8I). Therefore managing the project cost is so important that it may affect the overall quality of a translation project. Dunnes continues that current approaches to budgeting the translation and localization projects are problematic. Standard project management budgeting contains not only the aggregated costs but also includes the contingency and management reserves.

Wysocki (2004, p.42) named four project management processes included in project cost management as follow:

Resource planning: Unlike Helden's notes in table 6, this step is added by Wysocki and refers to resources required to complete the work of the project. However this definition is vague and ad hoc, the resources required in a translation project normally consist of time, cost, human resources (translators). Therefore resource planning is also applicable to defining responsibilities where managers decide to give the available translators a new project based on the available resources. In OTM system this step is automated and the required resources are listed for the translators and clients.

- Cost estimating: This is driven by the resource planning process. Translation manager sets cost estimation in the same way as has been done for the time estimation of the project. It is normally based on the standard or localized and pre-defined costing tables where sometimes the overall cost of a translation project is the word counts.

- Cost budgeting: This is another process in project cost management which deals with the various project tasks and the money required for them. Translation manager will set a different budget for the glossary making or editing phase.

- Cost control: As its name says, it is about controlling the overall cost of the project where there are many changes in the cost of project tasks throughout the life cycle of the translation project. These changes should be controlled and passed from a logical standard that allows overflow for the task cost in a project event.

\section{Translation Cost Evaluations}

Robinson(2003, p. 17) elaborated that above all "cost controls virtually all translation". Take for instance, a transaltion which is too expensive for the customer will not be done, while on the other hand a translation which is too cheap for the translator may not get done either. Therefore, cost evaluation is necessary to approve that the defined price tag for a translation project is fair to everyone included.

\section{Cost Management in Action}

Translation cost is measured on the basis of different factors. According to Gouadec (2007, p. 203), the basis for calculating translation costs and rates is usually around counts inherited from the days of the 
printing industry, including:

- number of words,

- number of signs,

- number of standard or 'real' pages (as opposed to 'physical pages', which may not be full pages) on the basis of 250 or 300 words per page - which amounts to a fine rate per word.

The standard implicitly adopted by the English and American translation industry is 250 words per page $(25 \times 6.5$ inch lines, with double spacing, and pica 10 font $)$, a throwback to the printing and typing era (Gouadec, 2007, p. 203).

Differences in counts are also applied to line length, which may depend on paper format and standard margin definitions. Some of these standard definitions are as follows:

- number of standard lines based on 60 characters per line - the standard reference in Belgium, for instance,

- number of standard sheets (25 lines of 60 characters each, i.e. 1500 signs - the standard reference in the publishing industry - or 30 lines of 60 characters each, i.e. 1800 signs).

However, the count may also include items such as:

- subtitles,

- menu lines,

- lines of code,

- minutes of dialogue - unless the calculation is based on a transcript and therefore on the number of words,

- reels,

- $\quad$ items (translation of legends, tables, lists, etc.),

- bits (used in software localization),

- $\quad$ and also people who count by jobs, hours or days.

There is no pre-defined standard to inscribe it on all translation/localization projects for the purpose of word-counting. Word-count norms are different from one another. Very different vocabularies are used in different genres of translation such as technical translation and literary translation. Therefore tariffs for these categories are often open to discussion and negotiation.

According to Gouadec(2007, p. 202), one method of calculation is based on source material volume, irrespective of the source language. Therefore, the number of items is multiplied by the flat rate per item. This is referred to as 'source unit' calculation. It makes it easier for the work provider to know where he stands. Another method known as 'target unit' calculation consists in basing the calculation on the translated volume, irrespective of language. The term 'expansion ratio' refers to the difference in the number of words between the target and the source text and the translator needs to take it into account.

Languages such as Persian are typically good examples of increase in the number of words in translation. Although Persian or French languages are known as poetic languages and more words are used in their texts, serious research has shown that the number of words can vary according to the translator's professional capacity. Gouadec also commented that work providers are often worried about translators who deliberately spin out their translation as much as possible. So, the best method is to agree on a pro rata calculation applied to the source word count.

These days, the method of multiplying the average number of words per line by the average number of lines per page, then multiplying the result by the number of pages is no more functional for modern translation industry. These different methods of word counts lead to a discussion on the merits of this or that application, from the translator's or the client's point of view. The idea of counting any signs in the page is sometimes boring in the minds of professional translators, because it gets in the way of the real job which is creating a remarkable equivalent experience for the target readers. The value of 
translation is measured by its feeling, consistency, discipline, and beauty not the actual number of words and signs.

\section{Project economics}

Project economics is a term to address the budgeting of the translation project. According to Gouadec (2007, p. 8I) in most translation projects, the payment and budget follows an early contract between the work provider and the translator thus the translator's financial liability is limited to the invoice total.

The budgeting in traditional translation project management was doomed to the blind contract or word counts of the translation product. In blind contract between the customer and the translator, an estimated range of cost and time is set, while the translated product may take more or less time and cost at the end.

On the other hand, the word-count method was also an amateur approach, where sometimes the translators over-translate a project to achieve more payment. There is no pre-defined costing "recipe" for all translation projects as it is determined by the structure and uniqueness of each project (Harkness, Behr, \& Lui, 2010).

Project economics which is not limited to the budgeting line of translation project, also includes other factors such as outsourcing, automatic cost measurement, and translator's payment. Before investigating these terms, a translation project needs a work out plan for its commercial policy and strategy in order to know its potential finance and to provide a platform for future advertising campaigns (Gouadec, 2007):

- Define tariffs and a billing policy: It refers to the policy that affects the company's future cash flow. Although defining a preset standard billing and tariffs policy looks like a tidy and managed decision, the uniqueness of translation projects is way far from setting preset tariffs for every project type. Some projects require additional costs and human resources and the uncertainty of a translation project avoids it, while it is actually against democratic standards of a project.

- Determine the resources required: This refers to allocation of resources in a translation project which consist of translators, technical writers, editors, proofers, translation manager, computer sources, and premises. This idea is about forecasting the required resources appropriate for a translation project, while it is not an objective approach. It is also counted as a manager task to decide the resource requirements. Thereafter, it may include underestimation and overestimation of project resources which are types of a blind estimation and against the free and online selection of resources.

- Choose the premises with utmost care: It is about careful estimation of budgeting through a translation project, in order to avoid blind estimation of costs, additional charges, taxes, insurance, energy etc. Incorrect estimation of required project budget may ruin the agency's image and dissuade the customers from future contracts.

- Work out the financial projections: Financial projections refer to income on the one hand and estimated costs on the other. These projections report financial sustainability of the project. The payment rate in translation management is fully subjective and it depends completely on the contract between the customer and translator(s). Software products such as Projetex or TOM provide many features related to the financial cycle of a project and assist the translator or manager to add an invoice for a project, while the customer should pay the invoice before the translation project starts. There are some modules like AnyCount or CATCount to assist the translator to find the word counts and a close estimation of project cost. 
- Work out the operating charges: Operating charges in a translation project may include purchases, external services, taxes, staff costs, financial charges, and depreciation. Calculation of operation charges in a translation project can vary according to the following factors:

- Work out how to finance investment: Initial sources of investment for a translator may be few, but in most cases it would be enough for a startup. These sources may include subscriber shares, funds from family and friends, governmental grants, banks or other sorts of loans. Therefore, either the translators decide what share of the workload they can take on and find out what share of the cake they can get, or they decide what share of the cake they want and what cost will have to be paid in terms of investment, training or retraining (Gouadec, 2007, p. I20).

- Complete all the legal formalities: This process is not directly related to the payment system or finance of the project, but it is a permission to do business. Legal forms like registration of translation organization permit the company to receive offers and continue its business in legal terms. It results in higher confidence from the customer as they know the organization is authorized by the government.

Further to above discussion, there is no set system or rule currently in place in order to be used to produce word counts and it is the main reason why a customer gets different project invoices from different translation agencies. The tools for these agencies are internal and private, while this unclear state of price tagging may affect the customer's mind, as they may think most of these prices are unfair.

Moreover, if a translator produces a cheaper invoice, then the customer might think of it as translation with lower quality. From usual Word Count tools like MS Word to technical tools such as Trados, it is hard to generate a similar result, for these tools have their own methods of counting. As an example in MS Word, the software will not count the boxes, tables, and figures, thus it ends in a lower count.

Other tools ignore items like embedded objects, headers, symbols and tags. On average, MS Word produces the lowest word count compared to Trados and Wordfast. Wordfast and PractiCount and Invoice produce higher word counts (Bologna, 2010).

Table 2 Specifications of Word Count tools (adopted from WinTranslation)

\begin{tabular}{|c|c|c|c|c|c|c|}
\hline & \multicolumn{6}{|c|}{ Word Counting Breakdown } \\
\hline & $\begin{array}{c}\text { Numbers \& } \\
\text { Symbols }\end{array}$ & $\begin{array}{c}\text { Footnotes/ } \\
\text { Endnotes }\end{array}$ & $\begin{array}{c}\text { Headers/ } \\
\text { Footers }\end{array}$ & $\begin{array}{c}\text { Text in } \\
\text { Text Boxes }\end{array}$ & $\begin{array}{c}\text { Embedded } \\
\text { Objects }\end{array}$ & Tags \\
\hline MS Word & Yes & No & No & No & No & Yes \\
\hline Trados & No & Yes & Yes & Yes & No & No \\
\hline Wordfast & No & Yes & Yes & Yes & No & Yes \\
\hline $\begin{array}{l}\text { PractiCount } \\
\text { and Invoice }\end{array}$ & Yes & Yes & Yes & Yes & Yes & $\begin{array}{l}\text { Both (ability to } \\
\text { include/exclude } \\
\text { tag counts in } \\
\text { HTML files) }\end{array}$ \\
\hline
\end{tabular}

Economics of translation project is not limited to setting invoices, other branches like online payments for customers and staff members are also valuable to a project management system.

The idea that a customer needs to go to the bank in order to pay the project cost is ridiculous. This method of payment is ancient and out of sync, while it takes time and imposes much more cost on the system. Today, the money transaction is the easiest and fastest part of the project. Online banking and online payments assist project handlers to manage project costs with ease and speed.

Costing process in translation projects regularly depends on the terms of payments which are agreed in advance. A mutual understanding of pricing structure must have been confirmed by the 
customer and translator(s), before the project is actually started. Some companies send proper invoice to the customer after the initial analysis of translation project and expect a full payment of the project, as it is an obligation for any further progress (Samuelsson-Brown, 2006, p. 77).

The invoice payment in translation management and freelancing are at opposite ends of the scale, for in the latter the payment is after the project completion. The difference is not only in the time of the payment, but it implies the reliability of project management system in the customers' minds. When a translation project is offered to a freelancer, they reach an agreement on the pricing method but the freelancer will be paid after the translation is done and checked by the customer. Therefore, there is no pay back insurance for both the freelancers and customers.

Back to management system the paid invoice may not be normally withheld or returned to customers, as the group of translation is working on the project, and the project cancelation will not be tolerated by the system. Moreover to this challenge, in modern translation management systems, freelancers and translation groups can bid for a project on which they can set a custom payment, and the customer on the other side is free to choose the best price among the ready translators' bids.

There is no convincing evidence that democracy can have a noticeable impact on the economies of societies. While, on the other side, countries like China, Singapore, and South Korea often claim that nondemocratic systems are better at economic growth. The idea that imperialism is the only and affective reason for these countries to have a growing economy, is subjective and with no convincing study. What is clear about democracy and the wealth growth in countries is that a friendly economic climate generates faster economic growth rather than a harsher political system (Sen, 1999).

The economic growth in nondemocratic environment is more about harsh authorization and hardworking rather than an open market with equity in its members. Back to translation management, the change from a self-managing and freelancing into participating in a free and open management system mostly results in economic growth along with friendly workplace.

\section{Conclusion}

Different people have different opinions toward translation management powered by software products. They question the reasons for using these products in translation project cycle. To be fair, they have the full right to ask for the causes and effects before they are assured in order to change their work structure. Similarly, many translators are not good with computers and online work environments, thus they need convincing answers before anyone can expect them to use any translation management product.

Cost management as a sub utility of a bigger picture named 'translation project management', can offer a systematic and comprehensive management procedure that surely affects the way everyone treats translation. Translation is not a hobby anymore and it should be taken seriously as a profession where the exchange rates and project costs are measured based on pre-defined translation standards. The cost policy will be clear to the customer and it helps translators to avoid committing over-translations or any other unethical actions. The management of translation costs can keep the translation quality high as it increases the productivity and profitability of translation works.

\section{Works Cited}

Bologna, S. (2010). Translation Word Count - Why do Word Counts Vary from Agency to Agency? Retrieved Sept 30, 2012, from WinTranslation: http://www.wintranslation.com/articles/ translationarticles/translation-word-counts/

Dunne, K. J., \& Dunne, E. S. (20II). Translation and Localization Project Management: The Art of the Possible. John Benjamins Publishing.

Dutta, M. (2005). Cost Accounting: Principles And Practice. Pearson Education India. 
Gouadec, D. (2007). Translation As a Profession. Amsterdam: John Benjamins Publishing Co.

Harkness, J., Behr, D., \& Lui, A. (2010, Sept 9). Translation: Translation Management and Budgeting. Retrieved Oct I, 2012, from Cross-Cultural Survey Guidelines: http://ccsg.isr.umich.edu/ trans_budg.cfm

McKay, C. (2006). how to succeed as a freelance translator. Lulu.com.

PMI. (2008). A Guide to the Project Management Body of Knowledge (PMBOK guide). Pennsylvania: Project Management Institute, Inc.

Samuelsson-Brown, G. (2006). Managing Translation Services. Multilingual Matters Publishing.

Sen, A. (1999). Democracy as a Universal Value. Journal of Democracy. 